\title{
Telemedicine in the Time of COVID-19 Pandemic
}

\author{
Khalid Masud Gondal ${ }^{1}$ and Shehla Shaukat ${ }^{2}$ \\ ${ }^{1}$ Department of Surgery, King Edward Medical University, Lahore, Pakistan \\ ${ }^{2}$ Department of Dermatology, Unit - I, King Edward Medical University, Lahore, Pakistan
}

Coronavirus disease (COVID-19) started in the city of Wuhan, China in December 2019, as of $25^{\text {th }}$ March, 2020 COVID-19 has affected many countries across the world with 414179 confirmed cases and 18440 deaths globally and more than 1102 confirmed cases and 8 deaths in Pakistan according to World Health Organization (WHO) and National Institute of health (NIH) Pakistan. ${ }^{1,2}$ It is a mild to severe respiratory illness that is caused by Severe Acute Respiratory Syndrome Coronavirus 2 of the genus Betacoronavirus and is transmitted chiefly by contact with infectious material (respiratory droplets); characterized by fever, cough and shortness of breath which may progress to pneumonia and respiratory failure. The spread of virus through contacthas made many countries to go under lockdown requiring people to stay home. At this time, the healthcare system has to offer medical assistance virtually by emplying telemedicine services. Telemedicine may sound new at the moment but it had been in practice for many years, though it never gained the present momentum induced by the outbreak of COVID-19.

Telemedicine, telehealth or virtual visit is a video visit to a health care provider over a secure network. The patient can access the doctor by a website or phone app. The option of text messages between the two is also an option. This facility is provided by hospitals and clinics for the patients who cannot reach these facilities especially in case of national disaster. This technology is useful in the time of COVID-19 pandemic and many specialities such as medicine, surgery, dermatology, paediatrics and psychiatry can use it to distant-treat patients by listening to the patients' complaints, looking at the lesions and assessing to reach a diagnosis. Multiple softwares are available for this use, some developed by hospitals and Institutes, some by commercialvendors and someby non-commercial free-available developers that however require to be acknowledged at the end of each consultation.

Cyber consultation for people concerned about coronavirus eliminates the need for a hospital visit in this time of mandatory social distancing. The goal is to keep people with minor ailments out of the hospital to avoid their exposure to Corona virus which has proved to be fatal for thousands across the world.

Correspondence to: Dr. Shehla Shaukat, Department of

Dermatology, Unit-I, King Edward Medical University,

Lahore, Pakistan

E-mail: shehla786@hotmail.com

Received: March 28, 2020; Revised: April 01, 2020;

Accepted: April 01, 2020

DOI: https://doi.org/10.29271/jcpsp.2020.04.349
Electronic intensive care unit (e-ICU) monitoring program is already in place in many countries. It (and similar programs) helps the physicians and nurses to monitor patients in ICUs without coming in direct contact with them. Many countries are also using the two-tablet approach for ICU and COVID-19 affected patients to reduce the healthcare workers' contact. One digital device is given to the patient and the other to healthcare personnel. Both of them can communicate on their tablet devices. ${ }^{3,4}$

The disadvantage of telemedicine is that physical examination, laboratory or radiological tests cannot be performed virtually. Many surgical and orthopaedic procedures cannot be performed as well without a visit to the hospital. It is a new and unfamiliar/unconventional practice which makes the patients reluctant to use it. Lack of education, communication network availabilityand awareness also hinders its acceptance by the people at large. This might be the most important hindrance in the Pakistani scenario.

It is our duty to provide care to community and dispel their concerns regarding coronavirus. Various institutes in Pakistan have taken the initiative of commencing the telemedicine services and providing 24/7 service, regarding general medicine, general surgery, orthopaedic, cardiology, pulmonology, gynaecology, ENT etc.

In future, telemedicine units of these institutes can be linked to other peripheral centers (hub and spoke model). Considering the increasing workload on tertiary care hospitals, telemedicine can help in triaging patients, who really need referral to specialist care. This will reduce the burden on tertiary care hospitals and cost of patient care in terms of time and resources. Besides patient care, telemedicine may be used for medical education and distant learning/teaching. New techniques and procedures can be learnt through this. We hope that the use of telemedicine becomes frequent even after the pandemic fades. It is the way forward to make healthcare accessible and cost-effective. As the system will come out of infancy, hurdles and pitfalls e.g. practice integration, running costs and rules and regulations for good ethical practice etc. are likely to arise and these will need to be resolved by incorporating medical ethics, local customs and values.

\section{REFERENCES}

1. Available at: http://www.who.int/docs/default-source/ coronaviruse/situation-reports/20200325-sitrep-65covid-19.pdf?sfvrsn=2b74edd8_2

2. Available at: http://www.nih.org.pk/wp-content/up loads/2020/03/COVID-19-Daily-Updated-SitRep-26Mar-2020.pdf 
3. Hollander JE, Carr BG. Virtually perfect? Telemedicine for COVID-19. N Eng J Med 2020:1-3.

4. Langabeer JR II, Gonzalez M, Alqusairi D, Champagne-
Langabeer T, Jackson A, Mikhail J, et al. Telehealthenabled emergency medical services program reduces ambulance transport to urban emergency departments. West J Emerg Med 2016; 17:713-20. 